Guirguis, B. and Shehata, M. (2017) A new screening test to evaluate the presence of oxidizable sulphide minerals in coarse aggregates, Const. and Build. Mat. 154, 1096-1104 


\title{
A New Screening Test to Evaluate the Presence of Oxidizable Sulphide Minerals in Coarse Aggregates
}

Bassili Guirguis and Medhat H. Shehata*

Department of Civil Engineering, Ryerson University, Toronto, Ontario, Canada

Highlights

- A test method was proposed to assess the possible oxidation of sulphide-bearing aggregates.

- The proposed method produces two outputs to screen aggregates.

- The test was applicable for the thirty aggregates tested in this study.

- Possible improvements to the test methods are discussed.

\begin{abstract}
A simple screening test was proposed in order to test coarse aggregates for their potential to cause damage when used in concrete due to the oxidation of sulphide phases. The test involves submerging an aggregate sample in an oxidizing agent and measuring the mass loss. Samples with no known oxidizable sulphides showed a mass loss of $<1.0 \%$ after one week of testing at room temperature. Samples of oxidizable sulphides showed a mass loss higher than $3.5 \%$ and changes in the colour of the test solution. It is proposed that aggregates which achieve a mass loss of less than $0.50 \%$ and no colour change in the test solution be accepted.
\end{abstract}

\section{Keywords}

Sulphide-bearing aggregate; oxidation; oxidizing agent; test methods; mass loss

\section{Introduction}

Sulphide-bearing aggregates can cause severe deterioration to concrete if the sulphide phases oxidize. Sulphide phases are minor constituents found in some rocks. During the period from 1900 to 1950 [1], mundic rock was used as a coarse aggregate for concrete blocks to reduce the cost of 
construction in the Cornwall and Devon areas of England, as reported by Lugg and Probert [1]. Many engineers used this aggregate in concrete construction. This rock contained a sulphide mineral, which subsequently oxidized and proceeded to deteriorate the concrete. Chinchon et al. [2] reported that throughout the period from 1970 to 1972, some public works and buildings near Barcelona were deteriorated and the concrete used for these buildings was comprised of coarse aggregates containing a high content of pyrrhotite grains. In 1974, Berard et al. [3] investigated a concrete deterioration case in Montreal, Canada and reported that the petrographic analysis provided evidence of expansive minerals in the concrete foundations. In 1979 in South Africa, severe cracking and deterioration of concrete was reported in houses in the Penge area [4]. Oberholster and Kruger [4] reported that the aggregate used in the concrete mix contained a carbonaceous and iron sulphide mineral. In the last decade, a case of concrete damage due to oxidation of sulphide phases has been reported in Trois-Rivieres, Quebec, Canada [5, 6, 7, 8, 9, 10]. The aggregates contained various proportions of pyrite and pyrrhotite [8]. The deteriorated concrete showed pop-outs and a network of cracks known as map cracking on the foundations and walls [11]. Recently, a case of sulphide-related deterioration in the foundations of more than 400 homes was reported in Eastern Connecticut, USA [12].

Steger [13] reported that the oxidation of sulphide-bearing aggregates occurs at a relative humidity of $37 \%-75 \%$. The incorporation of this kind of rock as a concrete aggregate may lead to severe damage in concrete structures. The oxidation products can generate sulphate ions, which react with the hydrated cement products to form gypsum $[14,15,16]$, ettringite $[14,17]$ and thaumasite $[16$, 18, 4]. These phases cause disruptions in the concrete [5]. The most common types of sulphide minerals are pyrite, $\mathrm{FeS}_{2}$, and pyrrhotite, $\left.\mathrm{Fe}_{(1-\mathrm{x})} \mathrm{S}\right)$. 
The general chemical formula of pyrite is $\left(\mathrm{FeS}_{2}\right)[10,19]$ with a molecular mass of $119.98 \mathrm{~g} / \mathrm{mol}$. It is composed of $53.4 \%$ sulphur (S) and $46.6 \%$ iron (Fe) [10]. The chemical formula of pyrrhotite is $\left(\mathrm{Fe}_{1-\mathrm{x}} \mathrm{S}\right)[9,19]$, with $\mathrm{x}$ ranging from 0 to $0.125[9,20]$. This results in a range from the form $(\mathrm{FeS})$ with a molecular mass of $87.87 \mathrm{~g} / \mathrm{mol},(\mathrm{S})$ of $36.5 \%$, and $(\mathrm{Fe})$ of $63.5 \%$, to $\left(\mathrm{Fe}_{7} \mathrm{~S}_{8}\right)$ with a molecular mass of $647.16 \mathrm{~g} / \mathrm{mol}$, (S) of $39.6 \%$, and (Fe) of $60.4 \%$. Chinchon-Paya [21] demonstrated that pyrite particles are composed of $49.03 \%$ sulphur and $46.37 \%$ iron, while pyrrhotite particles are composed of $35.18 \%$ sulphur and $61.12 \%$ iron.

The oxidation of sulphide phases can be summarized as follows:

Equation (1) shows the oxidation of pyrite minerals following exposure to water and oxygen [6]:

$$
\mathrm{FeS}_{2}+15 / 4 \mathrm{O}_{2}+5 / 2 \mathrm{H}_{2} \mathrm{O} \rightarrow \mathrm{FeOOH} \text { (goethite) }+2 \mathrm{H}_{2} \mathrm{SO}_{4} \text { (sulfuric acid) }
$$

For pyrrhotite, a sulphate-rich solution and iron by-products are formed as follows [19]:

$$
\mathrm{Fe}_{(1-x)} \mathrm{S}+(2-\mathrm{x} / 2) \mathrm{O}_{2}+\mathrm{xH}_{2} \mathrm{O} \quad \rightarrow \quad(1-\mathrm{x}) \mathrm{Fe}^{2+}+\mathrm{SO}_{4}{ }^{2-}+2 \mathrm{x} \mathrm{H}^{+}
$$

Then, following equations (3) and (4), the ferrous iron $\mathrm{Fe}^{2+}$ oxidizes to form ferric iron $\left(\mathrm{Fe}^{3+}\right)$ which can precipitate out of solution to form ferric hydroxide if the $\mathrm{pH}$ is above 3.5 [9].

$$
\begin{aligned}
& \mathrm{Fe}^{2+}+1 / 4 \mathrm{O}_{2}+2 \mathrm{H}^{+} \\
& \mathrm{Fe}^{3+}+3 \mathrm{H}_{2} \mathrm{O} \quad \rightarrow \quad \mathrm{Fe}^{3+}+1 / 2 \mathrm{H}_{2} \mathrm{O} \\
& \mathrm{Fe}(\mathrm{OH})_{3(\mathrm{~S})}+3 \mathrm{H}^{+}
\end{aligned}
$$

The Ferrous iron can also get oxidized and precipitated as ferric oxyhydroxides, principally ferrihydrite and goethite [19]. Ferric iron can also participate in the oxidation process and oxidize more Pyrrhotite following equation (5) [19]:

$$
\mathrm{Fe}_{(1-x)} \mathrm{S}+(8-2 \mathrm{x}) \mathrm{Fe}^{3+}+4 \mathrm{H}_{2} \mathrm{O} \quad \rightarrow \quad(9-3 \mathrm{x}) \mathrm{Fe}^{2+}+\mathrm{SO}_{4}{ }^{2-}+8 \mathrm{H}^{+}
$$

If the aggregate is used in concrete, the sulphuric acid reacts with one of the hydrated Portland cement paste products - $\mathrm{Ca}(\mathrm{OH})_{2}$ - to form gypsum following equation (6) [15, 22]:

$$
\mathrm{Ca}(\mathrm{OH})_{2}+\mathrm{H}_{2} \mathrm{SO}_{4} \quad \rightarrow \quad \mathrm{CaSO}_{4} \cdot 2 \mathrm{H}_{2} \mathrm{O} \text { (gypsum) }
$$


The gypsum can then lead to more forms of sulphate attack.

Shnorhokian [23] established that the factors that lead to increases in the rate of oxidation include the exposure of new surface areas of the mineral, and the presence of oxygen and moisture. While pyrite and pyrrhotite are oxidizable phases, pyrrhotite is known to oxidize at a faster rate [21, 24]. Schmidt [25] illustrated that higher concentrations of oxygen, higher $\mathrm{pH}$, and smaller particle sizes lead to higher disintegration of iron sulphide phases. Craig [26] reported that the Vickers Hardness Number of Pyrite is 1505-1620 and 230-318 for Pyrrhotite.

Following the case that took place in Trois-Rivieres, Quebec, a protocol was developed to evaluate the potential oxidation of sulphide-bearing aggregates prior to being used in concrete [6]. The protocol consists of a chemical test to assess the total sulphur in the aggregate, an oxidation test to evaluate the oxygen consumed by the aggregate while kept in a cell with a limited volume of air, and an oxidation mortar bar test that involves testing mortar bars under conditions that promote aggregate oxidation and sulphate attack in the cement paste [27].

In terms of aggregate testing, a method proposed by Midgley was used to evaluate the presence of deleterious iron sulphide bearing aggregates in concrete [28]. In the test, the aggregates were spread over a Petri dish, covered with filter paper, and submerged in a limewater solution. If the aggregate contains oxidizable sulphide, bluish-green ferrous sulphides will begin to form after 30 minutes. When removed from the solution and exposed to the air, the formations oxidize and turn brown.

The ASTM C 641 iron-staining test, [29] uses iron staining to detect the presence of deleterious sulphide minerals, as reported by Seaton [30]. The test procedure involves enclosing the aggregate sample in filter paper and exposing it to a steam bath for 16 hours, after which the aggregate is removed. The stained filter is then visually examined using a standard stain index. A chemical test 
can be performed on the stains to quantify the results. The sample is considered to contain a deleterious amount of sulphide if the amount of $\mathrm{Fe}_{2} \mathrm{O}_{3}$ equals or exceeds $1.5 \mathrm{mg} / 200$-g. Ramos et al, [11] modified the Midgley test and ASTM C641 iron-staining test and used the modified tests to evaluate aggregates. For the Midgley test, a $3 \% \mathrm{NaCl}, 3 \% \mathrm{H}_{2} \mathrm{O}_{2}, 6 \% \mathrm{NaClO}$, and lime solution were used to oxidize 20 grams of each aggregate prepared in a $9.5 \mathrm{~mm}$ sieve and retained over a $0.600 \mathrm{~mm}$ sieve. The samples were left in the solution for up to one week. The following results were obtained: (i) the limewater solution produced very weak stains for all of the aggregates - after 30 minutes no ferrous sulphides were observed, (ii) the $\mathrm{NaCl}$ produced weak staining after four days, (iii) the $\mathrm{H}_{2} \mathrm{O}_{2}$ produced visible stains after three days, and (iv) the $6 \%$ $\mathrm{NaClO}$ solution produced observable staining after 30 minutes and heavy staining by day three. By the end of the test, the filter papers were almost entirely destroyed.

\section{Materials and Experimental Details}

\subsection{Materials}

Thirty-one different types of coarse aggregates with different sulphur contents were used in this study. The primary rock type, composition, and total sulphur content $\left(\mathrm{S}_{\mathrm{T}} \%\right)$ (determined by combustion) are listed in Table 1. The aggregates are divided into three categories:

1. Cat. 1: aggregates that are known to have high sulphide content or have caused deterioration when used in concrete.

2. Cat. 2: aggregates that are alkali-reactive (LIM 1 is alkali-carbonate reactive while LIM2 and GRAV1 are alkali-silica reactive).

3. Cat. 3: aggregates that have no known issues related to sulphide. 
Table 1: Aggregate Mineralogy and total sulphur $\left(\mathrm{S}_{\mathrm{T}} \%\right)$ content.

\begin{tabular}{|c|c|c|c|c|c|}
\hline $\begin{array}{l}\text { Cate- } \\
\text { gory \# }\end{array}$ & Agg. ID & Primary rock type & Composition* & Iron sulphur mineral & $\begin{array}{c}\text { Total sulphur } \\
\left(\mathrm{S}_{\mathrm{T}} \%\right)\end{array}$ \\
\hline 1 & GAB 1 & Gabbro & Entirely ore mineral & Po, Py, Ccp, Pn** & 20 \\
\hline 1 & GAB 2 & Gabbro & Entirely ore mineral & Po, Py, Ccp, Pn & 20 \\
\hline 1 & QTZ 1a & Quartz-biotite schist & $\mathrm{Qz}, \mathrm{Fsp}, \mathrm{Bt}, \mathrm{Ms}$ & Po, Py, Jrs, Lm & 1.50 \\
\hline 1 & QTZ 1b & Quartz-biotite schist & Qz, Fsp, Bt, Ms & Po, Py, Jrs, Lm & 0.54 \\
\hline 1 & GAB $3 * * *$ & Gabbro & $\mathrm{Pl}, \mathrm{Bt}, \mathrm{Qz}$ & Po, Py, Ccp, Pn & $0.73-1.28$ \\
\hline 1 & GAB $4 * * *$ & Gabbro & $\begin{array}{l}\mathrm{Pl}, \mathrm{Bt}, \mathrm{Qz}, \mathrm{K}-\mathrm{Fsp} \\
\text { Cal, Dol, }\end{array}$ & Po, Py, Ccp & $2.13-4.22$ \\
\hline 2 & LIM 1 & Dolomitic limestone & Clay minerals & - & 0 \\
\hline 2 & LIM 2 & Siliceous limestone & $\begin{array}{l}\text { Cal, Dolomite Cht, } \\
\text { Clay minerals }\end{array}$ & - & 0 \\
\hline 2 & GRAV 1 & Siliceous gravel & Sst, Qz, Grt, Db, Gns & - & 0 \\
\hline 3 & DOL 1 & Dolostone & Dol & Gp, Py & 0.150 \\
\hline 3 & LIM 3 & Limestone & Cal & - & 0.038 \\
\hline 3 & DOL $2 \mathrm{a}^{* * * *}$ & Dolostone & Dol & - & 0.007 \\
\hline 3 & DOL $2 \mathrm{~b} * * * *$ & Dolostone & Dol & - & 0.007 \\
\hline 3 & LIM 4 & Limestone & Cal & - & 0.046 \\
\hline 3 & DOL 3 & Dolostone & Dol & Gp, Py & 0.140 \\
\hline 3 & DOL 4 & Dolostone & Dol & - & 0.017 \\
\hline 3 & GRAV 2 & $\begin{array}{c}\text { Carbonate dominant } \\
\text { gravel }\end{array}$ & $\begin{array}{c}90 \% \mathrm{Cb} \\
10 \% \text { Siliceous }\end{array}$ & Py & 0.180 \\
\hline 3 & GNS 1 & Mafic gneiss & $\mathrm{Pl}, \mathrm{Bt}, \mathrm{Qz}, \mathrm{Amb}$ & Py & 0.110 \\
\hline 3 & GAB 5 & Gabbro & Act, Pl, Chl, Mag & & 0.039 \\
\hline 3 & ANRS*** & Anorthosite & $\mathrm{Pl}, \mathrm{Hbl}, \mathrm{Bt}$ & - & $0.04-0.06$ \\
\hline 3 & DOL 5 & Dolostone & Dol & - & 0.007 \\
\hline 3 & DOL 6 & Dolostone & Dol & Py & 0.30 \\
\hline 3 & LIM 5 & Limestone & Cal & - & 0.059 \\
\hline 3 & GAB 6 & Gabbro & Amp, Pl, Mag, Bt & Po, Py & 0.15 \\
\hline 3 & BAS 1a $* * * *$ & Basalt & Act, Pl, Bt, Chl, Mag & - & 0.027 \\
\hline 3 & BAS $1 b^{* * * *}$ & Basalt & Act, Pl, Bt, Chl, Mag & - & 0.027 \\
\hline 3 & QTZT & Quartzite & $\mathrm{Qz}$ & - & 0.024 \\
\hline 3 & LIM 6 & Limestone & Cal & - & 0.06 \\
\hline 3 & GNS 2 & $\begin{array}{l}\text { Granite to granite } \\
\text { gneiss }\end{array}$ & K-Fsp, Qz, Pl, Bt & - & 0.009 \\
\hline 3 & GRAV 3 & Siliceous gravel & Gns, Grt, Gab & - & 0.010 \\
\hline 3 & GRAV 4 & Siliceous gravel & $\begin{array}{l}\text { Mafic to intermediate } \\
\text { granite gneiss }\end{array}$ & - & 0.050 \\
\hline
\end{tabular}




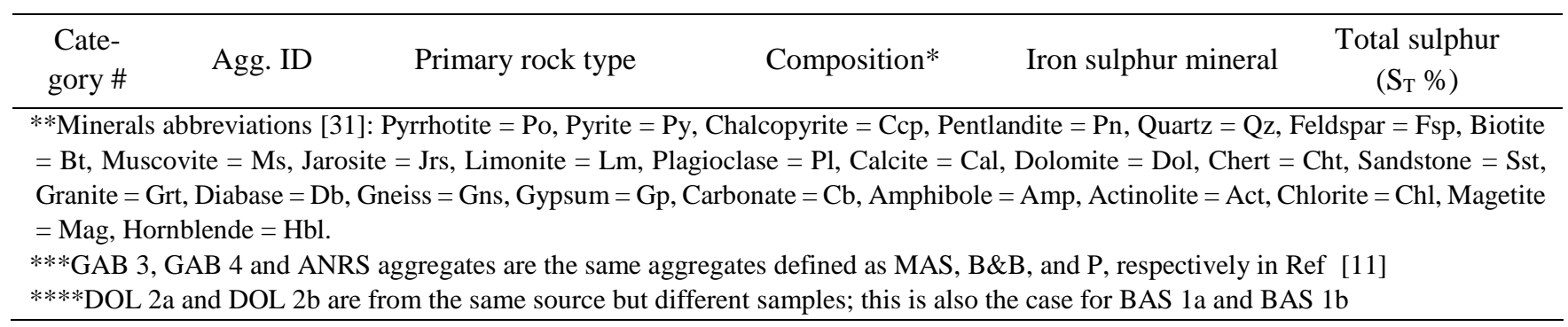

\subsection{Experimental Details}

\subsubsection{Aggregate Processing}

The aggregate samples were prepared following the procedures described in ASTM D 75 [32] and ASTM C 702 [33]. The representative coarse aggregate sample was crushed into different sandsize fractions as those used in the accelerated mortar bar test - ASTM C1260 [34]. From these fractions, $100 \mathrm{~g}$ was taken from either the fraction passing $4.75 \mathrm{~mm}$ and retained on $2.36 \mathrm{~mm}$ or the fraction passing $2.36 \mathrm{~mm}$ and retained on $1.18 \mathrm{~mm}$, and tested as described below. For aggregates DOL 2 and BAS 1, two samples from the same source - DOL 2a and DOL 2b or BAS $1 \mathrm{a}$ and BAS $1 \mathrm{~b}$ - were tested.

\subsubsection{Aggregate Oxidation Testing Procedures}

The aggregate oxidation test used here involves soaking a certain mass of aggregates of a certain particle size in an oxidizing solution for a given period, followed by washing over a designated sieve and drying in an oven at $80^{\circ} \mathrm{C}$ for one day to determine the mass loss after each cycle of soaking/drying. A 6\% sodium hypochlorite solution (household bleach) was used as the oxidizing solution. A mass of $100 \mathrm{~g}$ - of a specific particle size - from each aggregate was exposed to one liter of the solution at a solid to liquid ratio of 1:10. This high ratio was chosen to accelerate the rate and level of oxidation. The samples were tested in plastic bottles with a sealed lid in order to prevent evaporation when tested at $40^{\circ} \mathrm{C}$, and plastic household containers when tested at room temperature. 
During the first stage of this research, the test was run using a temperature of $40^{\circ} \mathrm{C}$ due to the assumption that higher temperatures would accelerate the oxidation, based on Steger's report [13] that the oxidation rate increases with increasing temperature. The aggregates were first washed and then oven-dried at $100^{\circ} \mathrm{C}$ for 24 hours. The samples were then allowed to cool for 5 hours, and the initial or zero-mass reading was taken (selected to be $100 \mathrm{~g}$ ). After that, the sample was soaked in the oxidizing solution for 12 days at $40^{\circ} \mathrm{C}$. At the end of the soaking period, the samples were taken out of the solution via draining then washed over a $600-\mu \mathrm{m}$ sieve. The aggregates were then placed in an oven at a temperature of $80^{\circ} \mathrm{C}$ for one day followed by 5 hours of cooling at room temperature. The last stage of the cycle would be the final sieving on a $600-\mu \mathrm{m}$ sieve and the determination of the retained mass. Following mass loss determination, the sample was kept at room temperature out of the solution for one day prior to the start of the next cycle. This resulted in a total cycle of 14 days or 2 weeks. The mass loss of the aggregates $\Delta \mathrm{m}(\%)$ after $\mathrm{n}$ wettingdrying cycles was calculated as follows:

$$
\Delta \mathrm{m}(\%)=\left[\left(\mathrm{m}_{0}-\mathrm{m}_{1}\right) / \mathrm{m}_{0}\right] \times 100 \%
$$

Where: $\mathrm{m}_{0}(\mathrm{~g})=$ original or zero mass of the aggregate at 0 cycles

$$
\mathrm{m}_{1}(\mathrm{~g})=\text { mass of aggregate after } \mathrm{n} \text { wetting-drying cycles }
$$

The aggregate GAB 4 was used to evaluate the effect of particle size on mass loss. The aggregate GAB 2 was tested once in bleach and once in water to assess whether or not oxidation can take place without an oxidizing solution (bleach). Three different particle sizes were tested: (i) $9.5 \mathrm{~mm}$ to $4.75 \mathrm{~mm}$, (ii) $4.75 \mathrm{~mm}$ to $2.36 \mathrm{~mm}$, and (iii) $1.18 \mathrm{~mm}$ to $0.600 \mathrm{~mm}$. After testing with GAB 4, the $4.75 \mathrm{~mm}$ to $2.36 \mathrm{~mm}$ particle size was chosen for testing.

In addition to measuring mass loss, selected solutions were tested for total iron (Fe) and sulphate $\left(\mathrm{SO}_{4}{ }^{2-}\right)$ ions in solution after the first cycle (two weeks) of the test using spectrophotometry. The 
solution samples were diluted at 1:100 to meet the detection limit of the instrument for $\mathrm{SO}_{4}{ }^{2-}$ which ranges from 0 to $70 \mathrm{mg} / \mathrm{L}$. For the detection of total iron ions, the samples were diluted at 1:500, to bring the concentration to the detection limit of the instrument - 0 to $3 \mathrm{mg} / \mathrm{L}$. The instrument used in this study is acceptable for water, wastewater and seawater analysis, according to the United States Environmental Protection Agency.

After running the test at $40^{\circ} \mathrm{C}$ and obtaining promising results, the testing period was shortened. The GAB 4 aggregate (size $4.75 \mathrm{~mm}$ to $2.36 \mathrm{~mm}$ ) was tested at three different temperatures: $23^{\circ} \mathrm{C}$, $40^{\circ} \mathrm{C}$, and $80^{\circ} \mathrm{C}$. The soaking period was changed from 12 to 5 days at $23^{\circ} \mathrm{C}$. The drying and preparation periods remain the same. After obtaining promising results with the GAB 4 aggregate, all 30 aggregates were re-tested at $23^{\circ} \mathrm{C}$ using the shorter cycle (one week). Moreover, a smaller particle size $(2.36 \mathrm{~mm}$ to $1.18 \mathrm{~mm})$ was also adopted in order to accelerate the results. The aggregate washing was carried out on a $300-\mu \mathrm{m}$ sieve. Selected solutions were examined for total iron $(\mathrm{Fe})$ and sulphate $\left(\mathrm{SO}_{4}{ }^{2-}\right)$ ions after the first cycle (one week) of the test using spectrophotometry.

\section{Results}

\subsection{Testing at $40^{\circ} \mathrm{C}$ Using Two-week Cycles}

As previously mentioned, the effect of particle size was evaluated using the GAB 4 aggregate. Two samples of the aggregate GAB $2(4.75 \mathrm{~mm}-2.36 \mathrm{~mm})$ were also tested in a sodium hypochlorite solution and water in order to investigate whether or not wetting and drying cycles, can promote oxidation without bleach. The results are illustrated in Fig.1 a and b. In Fig.1a, it is clear that the finer the sample, the higher the oxidation rate, especially at the beginning. The smallest size, $1.18 \mathrm{~mm}-0.600 \mathrm{~mm}$, was harder to handle as it stuck to the sides of the bottles, 
making it more difficult to drain. As a result, the $4.75 \mathrm{~mm}-2.36 \mathrm{~mm}$ size was chosen. Fig.1b shows that running the test without bleach (in water) does not produce significant mass loss, even when an aggregate with a very high level of oxidizable Sulphide (GAB 2) is tested.

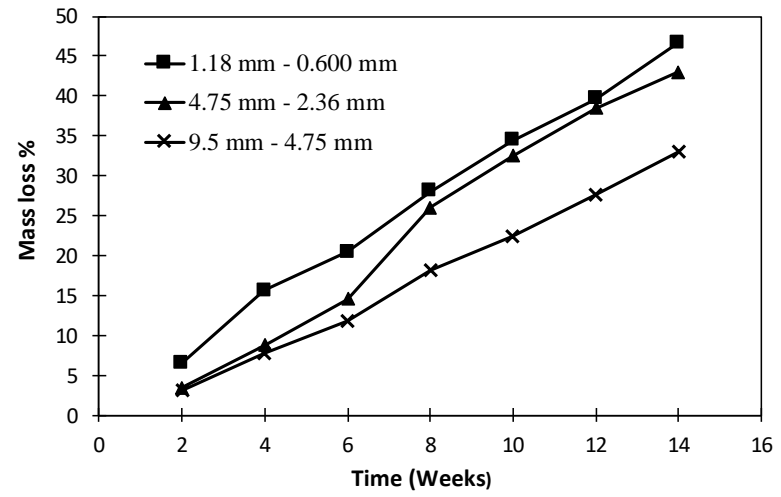

(a)

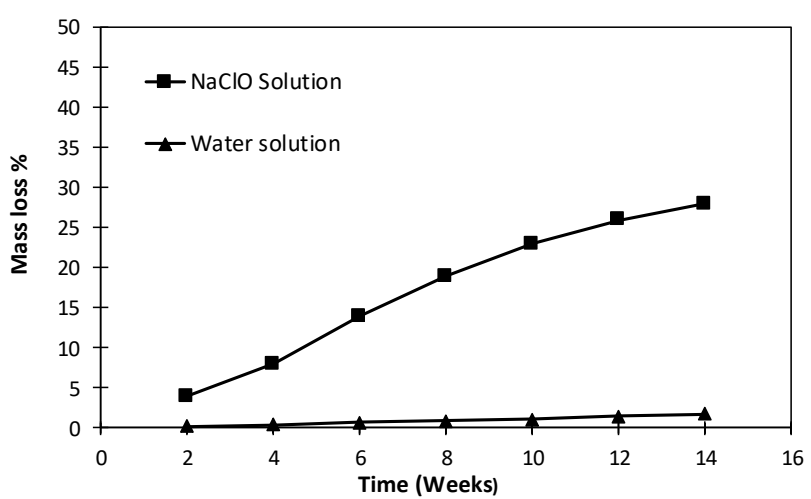

(b)

Fig. 1. (a) Effect of particle size on mass loss using GAB 4 aggregate, tested using 2-week cycles at $40^{\circ} \mathrm{C}$, (b) Effect of water and bleach ( $\mathrm{NaClO}$ solution) on mass loss using the GAB 2 aggregate.

The mass loss results for all thirty aggregates tested are listed in Table 2 (GAB 4 was not tested). The aggregates in this table are listed in descending order based on total sulphur content. The mass loss after two weeks (one cycle) ranged from $6.0 \%$ to $0.0 \%$. After 14 weeks (seven cycles), the mass loss ranged from $32 \%$ to $0.1 \%$. Based on the samples tested, a limit can be set to differentiate between aggregates that are known to contain oxidizable sulphide and aggregates that do not. For example, a limit of $1.0 \%$ can be used after two weeks or one cycle, or a limit of $3 \%$ after 14 weeks or seven cycles. In any case, the results reveal that a higher number of cycles leads to a larger range of mass loss. In addition to the mass loss, the changes in the colour of the bleach provided an excellent indication of the presence of oxidizable Sulphide, as shown in Fig. 2. The brown colour, following the first cycle, is obvious in all of the aggregates which contain oxidizable sulphide and sulphur content $\geq 0.54 \%$. Samples were also taken from the solution shown in Fig. 2 and tested for $\mathrm{pH}, \mathrm{Fe}$ and $\mathrm{SO}_{4}$ ions. The results are presented in Table 3. 
Table 2: Mass loss results and total Sulphur $\left(\mathrm{S}_{\mathrm{T}} \%\right)$ for aggregates tested at $40^{\circ} \mathrm{C}$ using particle size $4.75 \mathrm{~mm}$ to $2.36 \mathrm{~mm}$. Each cycle was two weeks (long cycle), and the solid to solution ratio was $1: 10$.

\begin{tabular}{|c|c|c|c|c|c|c|}
\hline Cat \# & Aggregate & $\begin{array}{c}\text { Total sulphur } \\
\left(\mathrm{S}_{\mathrm{T}} \%\right)\end{array}$ & $\begin{array}{l}\text { Mass loss \% } \\
\text { Cycle1 }\end{array}$ & $\begin{array}{l}\text { Mass loss \% } \\
\text { Cycle } 2\end{array}$ & $\begin{array}{c}\text { Mass loss \% } \\
\text { Cycle } 3\end{array}$ & $\begin{array}{c}\text { Mass loss \% } \\
\text { Cycle } 7\end{array}$ \\
\hline 1 & GAB 1 & 20.00 & 6.0 & 12.0 & 20.0 & 32.0 \\
\hline 1 & GAB 2 & 20.00 & 4.0 & 8.00 & 14.0 & 28.0 \\
\hline 1 & QTZ 1a & 1.500 & 5.0 & 9.00 & 12.0 & 14.0 \\
\hline 1 & GAB 3 & 1.000 & 3.0 & 6.00 & 8.00 & 11.6 \\
\hline 1 & QTZ 1b & 0.540 & 3.1 & 5.00 & 6.20 & 6.50 \\
\hline 3 & DOL 6 & 0.300 & 0.2 & 0.40 & 0.70 & 1.80 \\
\hline 3 & GRAV 2 & 0.180 & 0.0 & 0.00 & 0.50 & 1.60 \\
\hline 3 & DOL 1 & 0.150 & 0.5 & 0.50 & 0.90 & 1.20 \\
\hline 3 & GAB 6 & 0.150 & 0.0 & 0.60 & 0.60 & 0.90 \\
\hline 3 & DOL 3 & 0.140 & 0.0 & 0.00 & 0.50 & 1.50 \\
\hline 3 & GNS 1 & 0.110 & 1.0 & 1.40 & 1.80 & 2.40 \\
\hline 3 & LIM 6 & 0.060 & 0.2 & 0.20 & 0.20 & 1.20 \\
\hline 3 & LIM 5 & 0.059 & 0.0 & 0.00 & 0.00 & 0.10 \\
\hline 3 & GRAV 3 & 0.050 & 1.2 & 1.20 & 2.00 & 1.00 \\
\hline 3 & LIM 4 & 0.046 & 0.0 & 0.00 & 0.00 & 0.20 \\
\hline 3 & ANRS & 0.040 & 0.0 & 0.30 & 0.30 & 1.80 \\
\hline 3 & GAB 5 & 0.039 & 0.0 & 0.00 & 0.00 & 0.30 \\
\hline 3 & LIM 3 & 0.038 & 0.0 & 0.10 & 0.20 & 0.40 \\
\hline 3 & BAS 1a & 0.027 & 0.0 & 0.00 & 0.00 & 0.20 \\
\hline 3 & BAS $1 b$ & 0.027 & 0.3 & 0.50 & 0.80 & 1.20 \\
\hline 3 & QUTZT & 0.024 & 0.0 & 0.00 & 0.00 & 0.10 \\
\hline 3 & DOL 4 & 0.017 & 0.0 & 0.00 & 0.00 & 0.10 \\
\hline 3 & GRAV 3 & 0.010 & 0.0 & 0.00 & 0.00 & 0.10 \\
\hline 3 & GNS 2 & 0.009 & 0.0 & 0.00 & 0.00 & 0.20 \\
\hline 3 & DOL $2 \mathrm{a}$ & 0.007 & 0.0 & 0.00 & 0.00 & 0.30 \\
\hline 3 & DOL $2 b$ & 0.007 & 0.0 & 0.00 & 0.40 & 1.10 \\
\hline 3 & DOL 5 & 0.007 & 0.0 & 0.00 & 0.00 & 0.20 \\
\hline 2 & GRAV 1 & 0.000 & 0.0 & 0.00 & 0.00 & 0.40 \\
\hline 2 & LIM 1 & 0.000 & 0.0 & 0.00 & 0.00 & 1.50 \\
\hline 2 & LIM 2 & 0.000 & 1.0 & 1.00 & 1.00 & 1.00 \\
\hline
\end{tabular}




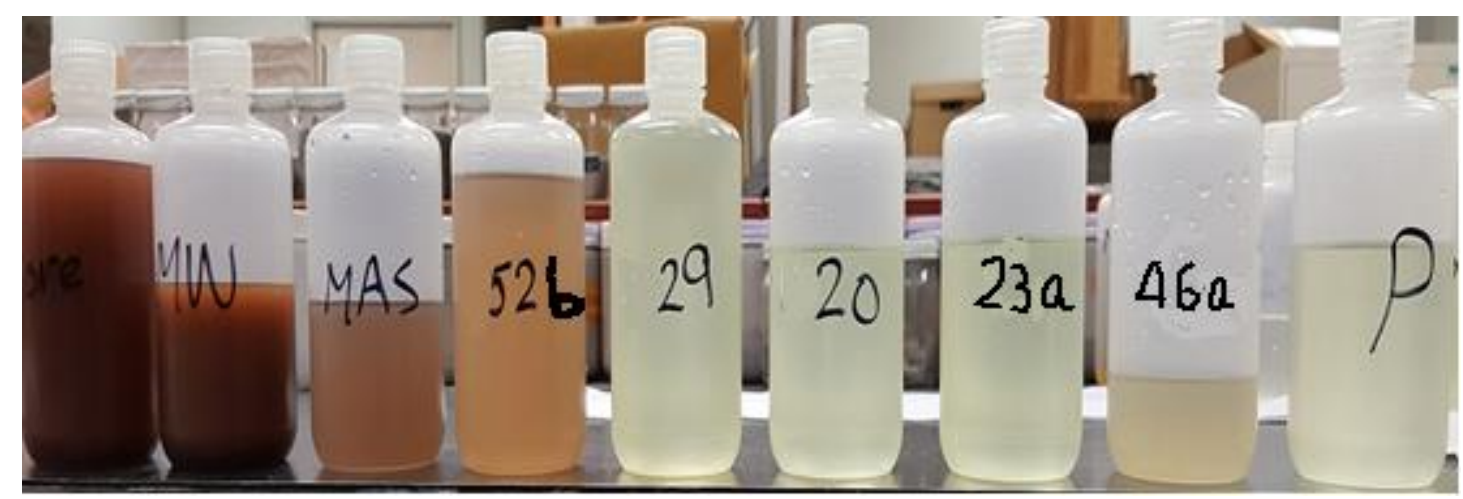

\begin{tabular}{|c|c|c|c|c|c|c|c|c|c|}
\hline Agg. & $\begin{array}{c}\text { GAB } \\
1\end{array}$ & $\begin{array}{c}\text { GAB } \\
2\end{array}$ & $\begin{array}{c}\text { GAB } \\
3\end{array}$ & $\begin{array}{c}\text { QTZ } \\
1 \mathrm{~b}\end{array}$ & $\begin{array}{c}\text { DOL } \\
6\end{array}$ & $\begin{array}{c}\text { DOL } \\
1\end{array}$ & $\begin{array}{c}\text { DOL } \\
2 \mathrm{a}\end{array}$ & $\begin{array}{c}\text { BAS } \\
1 \mathrm{a}\end{array}$ & ANRS \\
\hline $\mathrm{S}_{\mathrm{T}} \%$ & 20 & 20 & 1 & 0.54 & 0.30 & 0.15 & 0.007 & 0.027 & 0.04 \\
\hline
\end{tabular}

Fig. 2. The colour of the bleach after the first cycle (two-weeks) of the test. The brown colour is clear in all aggregates containing oxidizable Sulphur.

Table 3: Change in $\mathrm{pH}$, sulphur and iron in bleach after one cycle of 12 days soaking at $40^{\circ} \mathrm{C}$. The cycle reported here is cycle \# 1 . The initial $\mathrm{pH}$ of the solution was 12.2 .

\begin{tabular}{|c|c|c|c|c|c|c|c|c|c|}
\hline Aggregate & $\begin{array}{c}\text { GAB } \\
1\end{array}$ & $\begin{array}{c}\text { GAB } \\
2\end{array}$ & $\begin{array}{c}\text { GAB } \\
3\end{array}$ & $\begin{array}{l}\text { QTZ } \\
1 \mathrm{~b}\end{array}$ & $\begin{array}{c}\text { DOL } \\
6\end{array}$ & $\begin{array}{c}\text { DOL } \\
1\end{array}$ & $\begin{array}{c}\text { BAS } \\
1 \mathrm{a}\end{array}$ & $\begin{array}{c}\text { DOL } \\
2 \mathrm{a}\end{array}$ & ANRS \\
\hline $\begin{array}{c}\text { Total Sulphur } \\
\mathrm{S}_{\mathrm{T}} \%\end{array}$ & 20.0 & 20.0 & 1.0 & 0.54 & 0.30 & 0.15 & 0.027 & 0.007 & 0.04 \\
\hline $\begin{array}{c}\text { Mass loss after } \\
\text { cycle \#1 }\end{array}$ & 6.0 & 4.0 & 3.0 & 3.1 & 0.2 & 0.5 & 0 & 0 & 0 \\
\hline $\mathrm{pH}$ & 8.0 & 8.5 & 11.9 & 12.0 & 12.1 & 12.1 & 12.1 & 12.0 & 12.0 \\
\hline $\begin{array}{l}\text { Total iron ion } \\
(\mathrm{Fe})(\mathrm{mg} / \mathrm{L})\end{array}$ & 600 & 525 & 75 & 29 & 10 & 4.5 & 3.0 & 1.0 & 0 \\
\hline $\begin{array}{c}\text { Total sulphate } \\
\text { ion }\left(\mathrm{SO}_{4}^{2-}\right) \\
(\mathrm{mg} / \mathrm{L})\end{array}$ & 5200 & 4500 & 700 & 310 & 160 & 400 & 0 & 0 & 0 \\
\hline Sulphate/Iron & 8.7 & 8.6 & 9.33 & 10.7 & 16 & 88.9 & 0 & 0 & 0 \\
\hline
\end{tabular}

As shown in Table 3, the $\mathrm{pH}$ dropped significantly for aggregates that are known to have a high level of sulphide; i.e. GAB 1, and GAB 2. For GAB 3 and QTZ 1b, which are also known to have sulphide, the reduction in $\mathrm{pH}$ was not significant; suggesting that monitoring the $\mathrm{pH}$ is not suitable 
for all sulphide-bearing aggregates. This is because the solid to solution ratio used in this test is 1:10 (relatively high volume of solution) which requires many oxidation products (sulphuric acid) to produce a measurable reduction in $\mathrm{pH}$. It is clear that the higher the mass loss, the higher the level of sulphate and iron ions in solution. It is also interesting to see that the ratio of sulphate-toiron is in the range of 8 to 11 for aggregates with sulphide phases GAB 1, GAB 2, GAB 3, and QTZ 1b. For aggregates not known to contain sulphide, the ratio is different. This ratio does not correspond to the expected mass ratio of $\mathrm{S}: \mathrm{Fe}$ in pyrite or pyrrhotite. This is because the oxidation process produces a ferrous iron that oxides and precipitates in different forms, including ferric hydroxide, as per equations (3) and (4), and oxyhydroxides, such as ferrihydrite and goethite. The amount of dissolved iron determined using this test could be a limited amount of ferrous iron that has yet to be precipitated from the solution.

\subsection{Effects of Testing Temperature and Cycle Length}

The results from the tests conducted at a temperature of $40^{\circ} \mathrm{C}$ revealed promising results in terms of detecting the presence of oxidizable Sulphide; however, it was thought that it would be beneficial to accelerate the test in order to obtain results in a shorter time. The effects of testing temperature and a shorter soaking cycle were studied using the aggregate GAB 4 . The effect of temperature is shown in Fig.3a. As the figure shows, the early mass loss was higher at $23^{\circ} \mathrm{C}$, and the late mass loss was slightly higher at $40^{\circ} \mathrm{C}$. The reason for not obtaining a higher mass loss at a higher temperature can be explained using the work of Frais [35], who illustrated that at high temperatures, hypochlorite anions can decompose to chlorine and chlorate, which are less efficient oxidizers than hypochlorite. Based on the obtained results, it was decided to run the test at room temperature $\left(23^{\circ} \mathrm{C}\right)$. 
The effect of cycle length is shown in Fig.3b. The results reveal that using a shorter cycle produces a higher mass loss. Two weeks on the $\mathrm{x}$-axis of the graph represents one complete two-week cycle or two complete one-week cycles. Based on the obtained results, it was decided to test the samples using a one-week cycle at room temperature $\left(23^{\circ} \mathrm{C}\right)$. Moreover, a smaller aggregate, $2.36 \mathrm{~mm}-$ $1.18 \mathrm{~mm}$, was used to accelerate the results.

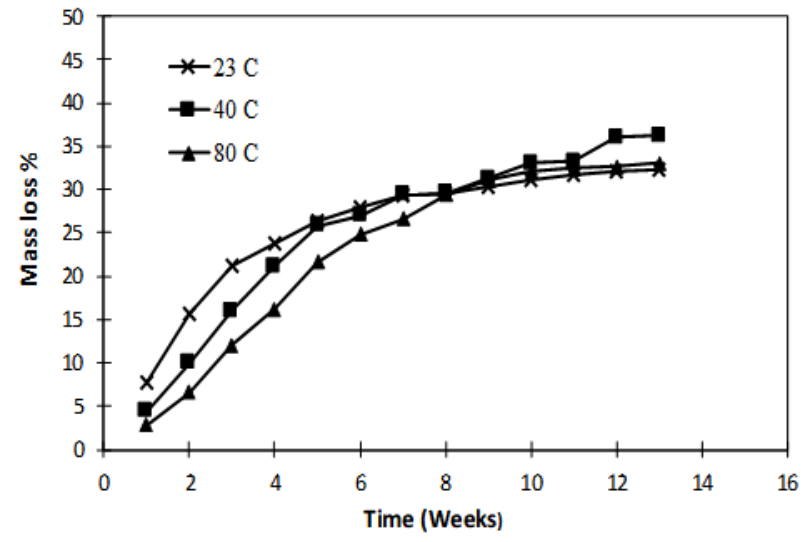

(a)

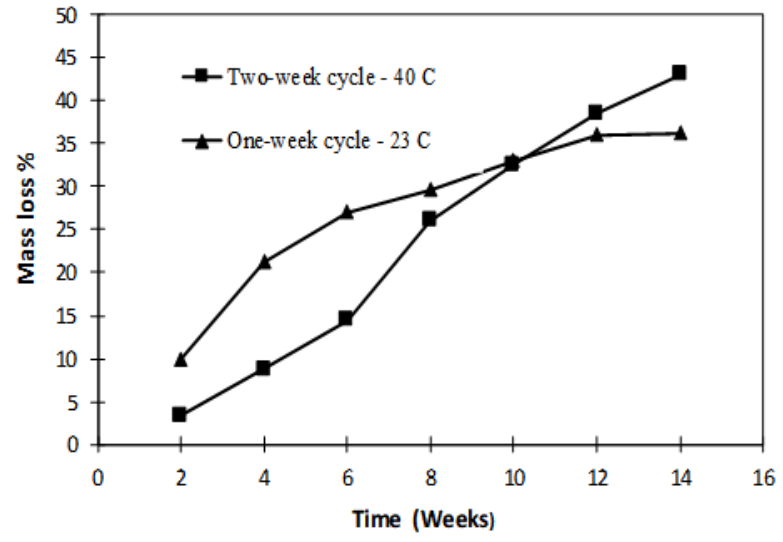

(b)

Fig. 3. (a) Effect of different temperatures on mass loss, (b) Effect of cycle length on mass loss. The tests were carried out using the GAB 4 aggregate, size $4.75 \mathrm{~mm}$ to $2.36 \mathrm{~mm}$.

\subsection{Testing at $23^{\circ} \mathrm{C}$ Using one-week Cycle}

The mass loss results are listed in Table 4 and the bleach colour for aggregates with and without sulphide are shown in Fig. 4. Finally, the dissolved sulphate and iron in solution are listed in Table 5. The sulphate-to-iron ratio for aggregates with sulphide phases is similar to the values obtained when testing at $40^{\circ} \mathrm{C}$ using the larger size fraction $(4.75 \mathrm{~mm}$ to $2.36 \mathrm{~mm})$. 
Table 4: Mass loss results and total Sulphur $\left(\mathrm{S}_{\mathrm{T}} \%\right)$ for aggregates tested at $23^{\circ} \mathrm{C}$ using particle size from $2.36 \mathrm{~mm}$ to $1.18 \mathrm{~mm}$ after cycles $1,2,3$. Each cycle was one week (short cycle), and the solid to solution ratio was $1: 10$.

\begin{tabular}{|c|c|c|c|c|c|}
\hline Cat. \# & Aggregate ID & $\begin{array}{c}\text { Total sulphur } \\
\left(\mathrm{S}_{\mathrm{T}} \%\right)\end{array}$ & $\begin{array}{c}\text { Mass loss \% } \\
\text { Cycle } 1\end{array}$ & $\begin{array}{l}\text { Mass loss \% } \\
\text { Cycle } 2\end{array}$ & $\begin{array}{c}\text { Mass loss \% } \\
\text { Cycle } 3\end{array}$ \\
\hline 1 & GAB 1 & 20.00 & 14 & 29.5 & 41.8 \\
\hline 1 & GAB 2 & 20.00 & 13 & 28.0 & 40.8 \\
\hline 1 & QTZ 1a & 1.500 & 5.3 & 9.10 & 12.4 \\
\hline 1 & GAB 3 & 1.000 & 4.5 & 6.70 & 8.90 \\
\hline 1 & QTZ 1b & 0.540 & 3.6 & 5.70 & 7.10 \\
\hline 3 & DOL 6 & 0.300 & 0.0 & 0.20 & 0.20 \\
\hline 3 & GRAV 2 & 0.180 & 0.0 & 0.00 & 0.00 \\
\hline 3 & DOL 1 & 0.150 & 0.8 & 1.00 & 1.30 \\
\hline 3 & GAB 6 & 0.150 & 0.2 & 0.40 & 0.60 \\
\hline 3 & DOL 3 & 0.140 & 0.0 & 0.00 & 0.00 \\
\hline 3 & GNS 1 & 0.110 & 0.6 & 1.00 & 1.30 \\
\hline 3 & LIM 6 & 0.060 & 0.1 & 0.20 & 0.30 \\
\hline 3 & LIM 5 & 0.059 & 0.0 & 0.00 & 0.10 \\
\hline 3 & GRAV 3 & 0.050 & 0.4 & 0.80 & 1.20 \\
\hline 3 & LIM 4 & 0.046 & 0.0 & 0.00 & 0.00 \\
\hline 3 & ANRS & 0.040 & 0.0 & 0.00 & 0.10 \\
\hline 3 & GAB 5 & 0.039 & 0.0 & 0.10 & 0.20 \\
\hline 3 & LIM 3 & 0.038 & 0.0 & 0.20 & 0.30 \\
\hline 3 & BAS 1a & 0.027 & 0.2 & 0.20 & 0.70 \\
\hline 3 & BAS 1b & 0.027 & 0.4 & 0.60 & 1.60 \\
\hline 3 & QUTZT & 0.024 & 0.0 & 0.00 & 0.00 \\
\hline 3 & DOL 4 & 0.017 & 0.0 & 0.00 & 0.00 \\
\hline 3 & GRAV 3 & 0.010 & 0.0 & 0.00 & 0.00 \\
\hline 3 & GNS 2 & 0.009 & 0.0 & 0.00 & 0.00 \\
\hline 3 & DOL 2a & 0.007 & 0.0 & 0.00 & 0.00 \\
\hline 3 & DOL $2 b$ & 0.007 & 0.0 & 0.00 & 0.00 \\
\hline 3 & DOL 5 & 0.007 & 0.0 & 0.00 & 0.00 \\
\hline 2 & GRAV 1 & 0.000 & 0.0 & 0.00 & 0.20 \\
\hline 2 & LIM 1 & 0.000 & 0.0 & 0.00 & 0.10 \\
\hline 2 & LIM 2 & 0.000 & 0.0 & 0.00 & 0.00 \\
\hline
\end{tabular}




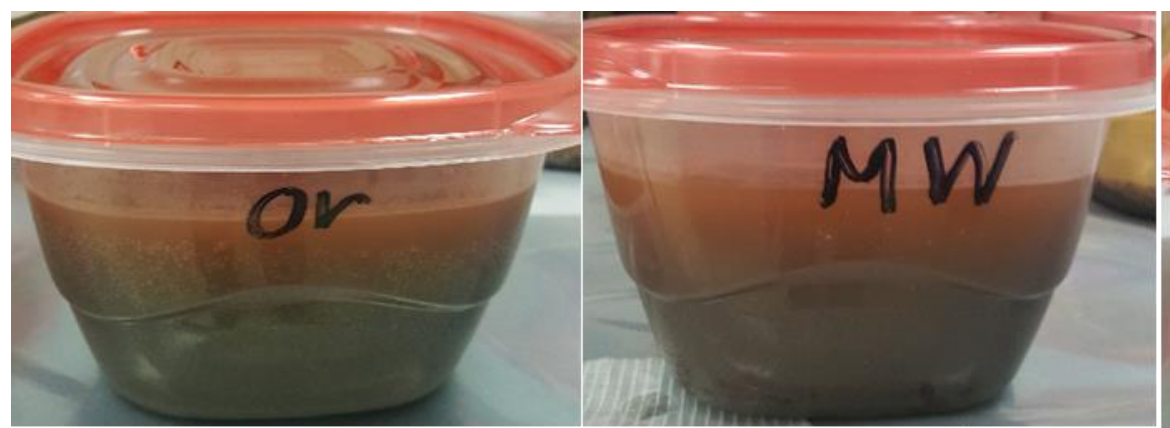

GAB 1

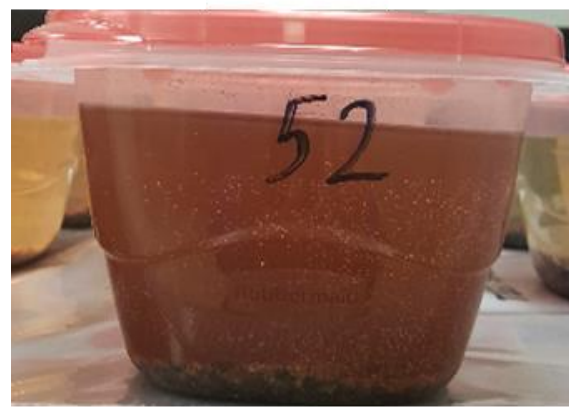

QTZ 1b

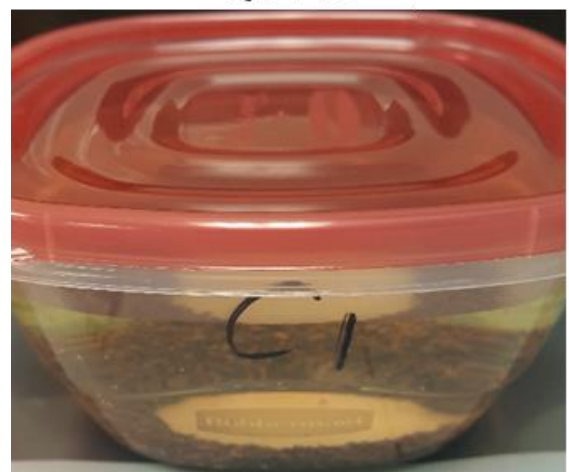

DOL 2a
GAB 2

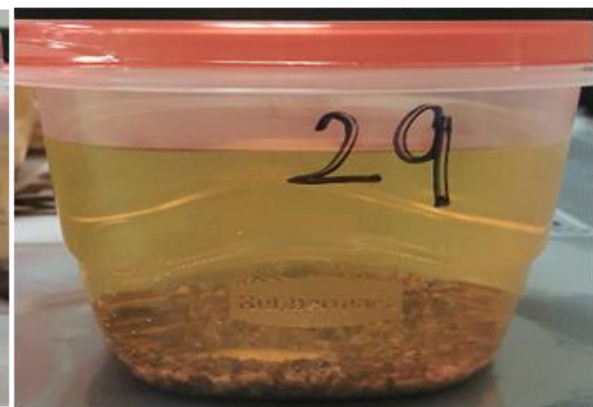

DOL 6

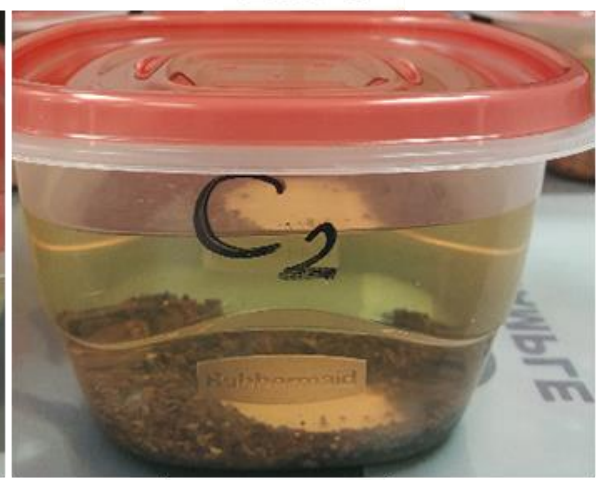

BAS 1a

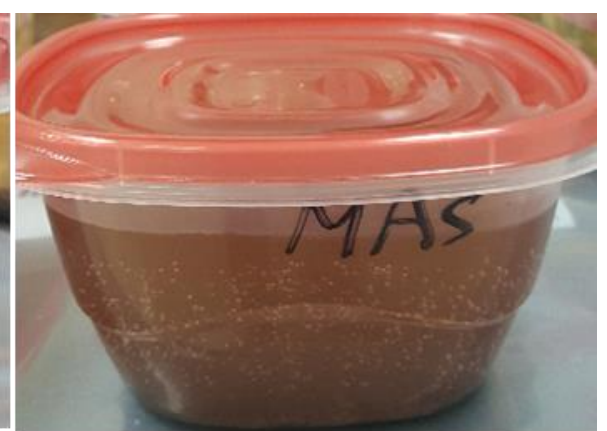

GAB 3

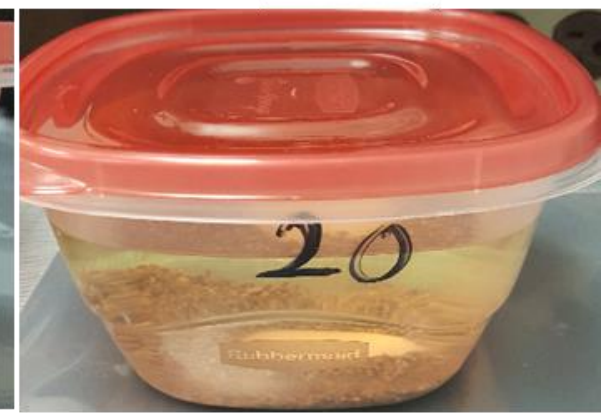

DOL 1

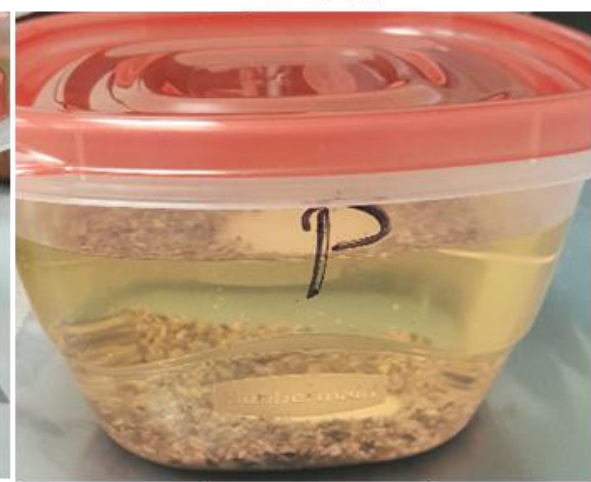

ANRS

Fig. 4: Colour of the test solution after the first cycle (one week) of the test at room temperature.

The results revealed that testing at room temperature $\left(23^{\circ} \mathrm{C}\right)$ provided faster oxidation or mass loss compared to a temperature of $40^{\circ} \mathrm{C}$ using a coarser fraction. A comparison between the long and short cycles is provided in Fig.5 ( $\mathrm{a}$ and b). Fig.5a illustrates the relationship between mass loss after 2 weeks of testing using the short cycle - representing 2 cycles - at $23^{\circ} \mathrm{C}$ using size $2.36 \mathrm{~mm}$ $-1.18 \mathrm{~mm}$ versus 2 weeks of testing using the long cycle - representing one cycle - at $40^{\circ} \mathrm{C}$ using 
size $4.75 \mathrm{~mm}-2.36 \mathrm{~mm}$. The aggregates GAB 1 and GAB 2, which consist mainly of sulphide phases, showed a much higher mass loss when tested using the short cycle at room temperature with the finer gradation compared to the longer cycle at $40^{\circ} \mathrm{C}$ with coarser gradation. The other aggregates followed a linear trend with a slope of 1.83 showing that two shorter cycles at room temperature using finer gradation produced almost double the mass loss obtained by testing the aggregates for one long cycle - two weeks - at $40^{\circ} \mathrm{C}$ using the coarser gradation.

Table 5: Changes in $\mathrm{pH}$, Sulphur, and iron in bleach after one cycle of 5 days soaking at $23^{\circ} \mathrm{C}$. The cycle reported here is cycle \# 1 . The initial $\mathrm{pH}$ of the solution was 12.4 .

\begin{tabular}{|c|c|c|c|c|c|c|c|c|c|c|}
\hline Aggregate & $\begin{array}{c}\text { GAB } \\
1 \\
\end{array}$ & $\begin{array}{c}\text { GAB } \\
2 \\
\end{array}$ & $\begin{array}{c}\text { GAB } \\
3 \\
\end{array}$ & $\begin{array}{c}\text { QTZ } \\
1 \mathrm{~b} \\
\end{array}$ & $\begin{array}{c}\text { DOL } \\
6 \\
\end{array}$ & $\begin{array}{c}\text { DOL } \\
1 \\
\end{array}$ & $\begin{array}{c}\text { BAS } \\
1 \mathrm{a} \\
\end{array}$ & $\begin{array}{c}\text { BAS } \\
1 \mathrm{~b} \\
\end{array}$ & $\begin{array}{c}\text { DOL } \\
2 \mathrm{a} \\
\end{array}$ & ANRS \\
\hline $\begin{array}{c}\text { Total Sulphur } \\
\mathrm{S}_{\mathrm{T}} \%\end{array}$ & 20.0 & 20.0 & 1.0 & 0.54 & 0.30 & 0.15 & 0.027 & 0.027 & 0.007 & 0.04 \\
\hline $\begin{array}{l}\text { Mass loss after } \\
\text { cycle \#1 }\end{array}$ & 14 & 13 & 4.5 & 3.6 & 0 & 0.8 & 0.2 & 0.4 & 0 & 0 \\
\hline $\mathrm{pH}$ & 8.2 & 8.8 & 12.0 & 12.2 & 12.3 & 12.3 & 12.4 & 12.3 & 12.3 & 12.3 \\
\hline $\begin{array}{l}\text { Total iron ion } \\
(\mathrm{Fe})(\mathrm{mg} / \mathrm{L})\end{array}$ & 685 & 585 & 80.5 & 35 & 12 & 5 & 2 & 2.5 & 1.0 & 0 \\
\hline $\begin{array}{l}\text { Total sulphate ion } \\
\left(\mathrm{SO}_{4}{ }^{2-}\right)(\mathrm{mg} / \mathrm{L})\end{array}$ & 6300 & 5600 & 800 & 400 & 200 & 1000 & 100 & 200 & 0 & 0 \\
\hline Sulphate/Iron & 9.2 & 9.57 & 9.94 & 11.4 & 16.6 & 200 & 50 & 80 & 0 & 0 \\
\hline
\end{tabular}

Fig. 5b emphasizes the same trend observed in Fig. 5a This graph compares mass loss using the two testing regimes for the same number of cycles. GAB 1 and GAB 2 showed much higher mass loss using three shorter cycles ( 3 weeks) at room temperature using the finer gradation. For the other aggregates, the relationship followed a linear trend with a slope of almost 1.0, suggesting that the mass loss is the same for both testing regimes using the same number of cycles, regardless of the length of the cycles. The results in Fig. 5 suggest that testing the fraction from $2.36 \mathrm{~mm}$ to $1.18 \mathrm{~mm}$ at room temperature provides quicker results and may result in more oxidation for materials with very high sulphide contents such as GAB 1 and GAB 2. 


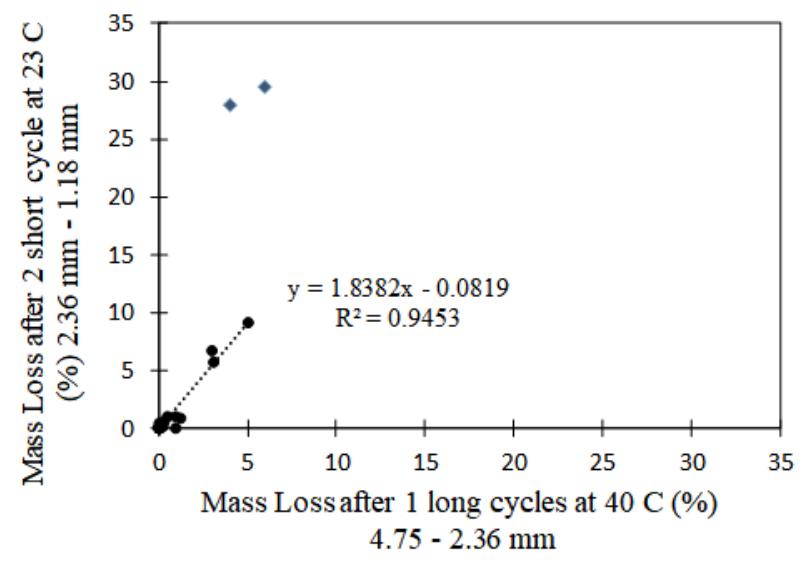

(a)

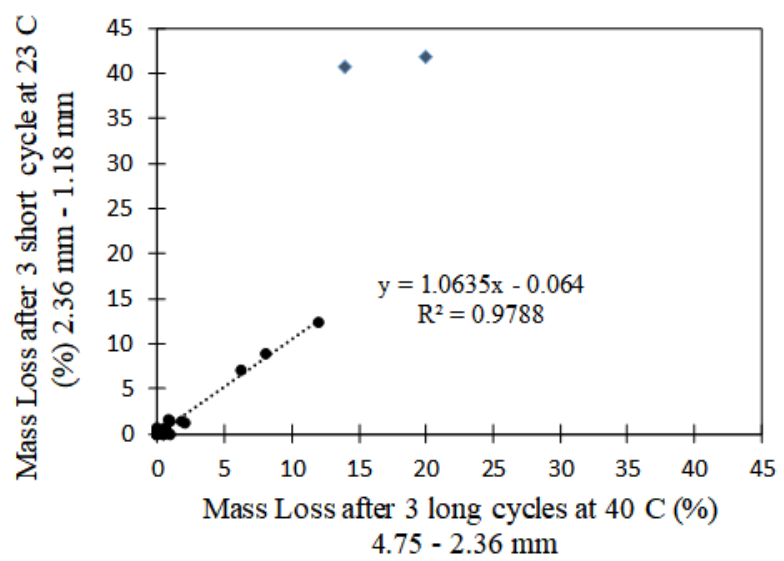

(b)

Fig. 5: Comparison of mass loss using the long and short cycle.

\section{Discussion}

The proposed test method presented in this paper can serve as a quick test to screen aggregates for their potential to oxidize. The results revealed that the test was able to distinguish aggregates with oxidizable sulphide from those without. Quicker results were obtained when the test was run at room temperature using a particle size of $2.36 \mathrm{~mm}$ to $1.18 \mathrm{~mm}$. The test was carried out using household bleach and containers with no observed overheating or issues related to safety. That being said, this method is open to optimization. For instance, testing a larger aggregate size or testing different fractions of particle sizes and calculating the weighted average of mass loss are ideas that can be pursued. In addition, testing masses greater than $100 \mathrm{~g}$ may provide better test result precision. In any case, the test in its current form provides an excellent indication of an aggregates potential to contain oxidizable sulphide.

The test provides two main outputs that can be used together to evaluate an aggregate: changes in the colour of the solution following the test, and mass loss. The mass loss results following one and three cycles of the test at $23^{\circ} \mathrm{C}$ using size $2.36 \mathrm{~mm}$ to $1.18 \mathrm{~mm}$ are shown in Fig.6 (a and b), respectively. The figures suggest that a limit of $1.0 \%$ can be used for the mass loss after one cycle 
and $2.0 \%$ after three cycles. The third cycle can be used if an aggregate exceeds the $1.0 \%$ limit after the first cycle. These limits help differentiate between aggregates with and without sulphide. While the lowest mass loss obtained for aggregates with known sulphide following one cycle was $3.6 \%$ - which is more than triple the suggested limit, the authors believe that a stricter limit can be adopted until more sulphide-bearing aggregates are tested. A $0.5 \%$ limit following one cycle and a $1.0 \%$ limit following three cycles are recommended. Only two out of 25 aggregates containing no sulphide would fail to meet a $0.5 \%$ limit. More detailed testing, including looking at the sulphur and iron in solution, petrographic examination, and quantitative determination of sulphide phases, would be recommended for aggregates that do not show changes in colour or mass loss. While not found in the aggregates tested here, some forms of iron phases or clay minerals within the aggregate may cause mass loss and a change in colour. In such cases, this aggregate will be screened as "requires further testing". More detailed testing can be used to identify the cause of the mass loss and change in colour. It should be noted that, two of the aggregates tested contain clay mineral, LIM 1 and LIM 2, and did not show mass loss or changes in the colour of the solution. The iron and sulphate in solution should be interpreted with caution. Although certain ratio of sulphate to iron were obtained here for samples with oxidizable sulphide, this does not mean that this is always the case, especially that ferrous iron produced during oxidation does not remain in solution as per equations (2) to (4). However, the presence of an appreciable amount of iron in solution (> $20 \mathrm{mg} / \mathrm{L}$ based on this study) may indicate that the aggregate has oxidizable sulphide phases. A lack of sulphate in solution is a strong indication that mass loss, if any, is not due to oxidation of sulphide phase. On the other hand, high sulphate in solution does not indicate the presence of oxidizable sulphide as this can be caused by another form of sulphate such as gypsum. 


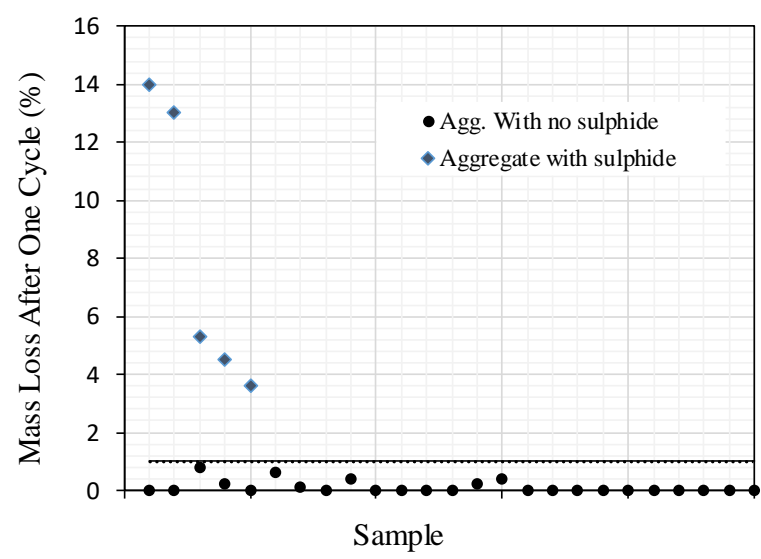

(a)

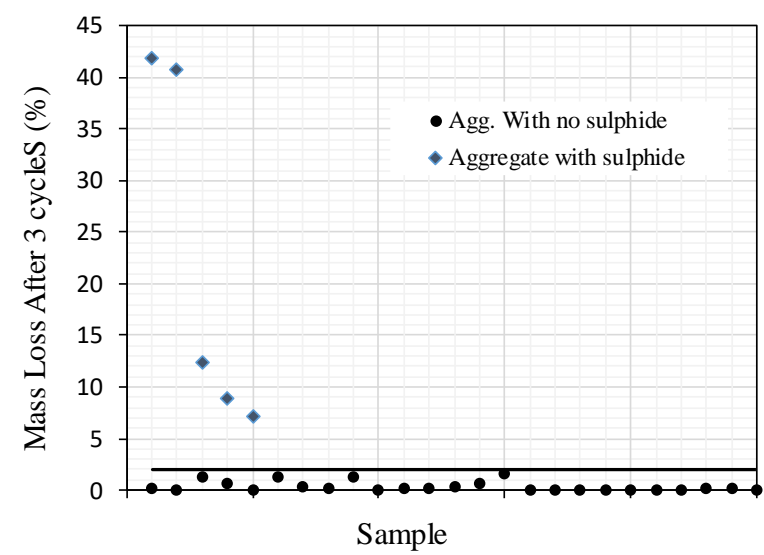

(b)

Fig. 6: Mass loss for the 30 tested samples after (a) one cycle or (b) three cycles of testing at $23^{\circ} \mathrm{C}$ using $2.36 \mathrm{~mm}-1.18 \mathrm{~mm}$ aggregates.

While a low level of total sulphur in aggregate has been suggested by some standards, e.g. $0.10 \%$ as proposed by Annex P of CSA A23.1-2014 [36], aggregate with higher sulphur content can have little or no oxidizable sulphide. Six of the aggregates tested here with no known oxidizable sulphide had a total sulphur content $>0.10 \%$. Four of these aggregates met the $0.50 \%$ mass loss limit while the other two had a mass loss between $0.5 \%$ and $1.0 \%$. There was no direct relationship between mass loss and total sulphur. This shows the benefit of using the proposed test as a second step after total sulphur determination.

Testing the aggregates DOL $2 \mathrm{a}$ and DOL $2 \mathrm{~b}$ as well as BAS 1a and BAS $1 \mathrm{~b}$ provided some indication of the anticipated variability between different samples from the same source. Both the DOL 2a and DOL 2b samples showed zero mass loss; however, sample BAS 1b showed a higher mass loss and higher sulphate and iron in solution compared to BAS 1a. It is not known whether this is due to minor differences in the sample compositions or the precision of the test method. The higher sulphate and iron in solution associated with higher mass loss for sample BAS 1b suggests 
that there is a minor difference in the composition of the two samples. In any case, the difference in mass loss was not large, particularly after the first cycle (both samples had mass loss $<0.5 \%$ ). In summary, the test proposed in this study can be used as a screening tool. Aggregates with a limited mass loss $(<0.5 \%$ after one cycle $)$ and no change in the colour of the solution can be considered to contain no appreciable amount of oxidizable sulphide phases. A limit of $1.0 \%$ can be used after three cycles for aggregates failing the $0.5 \%$ limit after cycle 1 . Aggregates that fail such criteria should be exposed to more testing, including the total sulphide sulphur determined chemically, petrographic analysis, or the test protocol described by Rodrigues [6]. It is recommended that more aggregates of different geological compositions be tested in order to examine the applicability of the test to a wide range of aggregates and perhaps revisit the acceptance limits. Moreover, using different particle sizes or larger sample mass are also options for enhancing the test method.

\section{Conclusions}

The following conclusions were drawn from the materials investigated in this study:

- The proposed test method is able to differentiate between aggregates with and without oxidizable sulphide phases.

- The finer the tested aggregate gradation, the larger the mass loss within a certain period of time.

- Testing at higher temperatures did not accelerate the oxidation. This is not related to the oxidation process, but to a change in the chemical composition of the sodium hypochlorite used as an oxidizing agent. 
- In its present form, the change in colour of the test solution and the mass loss after one week of testing at room temperature can be used to screen aggregates for their use in concrete: aggregate samples with a mass loss $<0.50 \%$ and no change in the test solution is considered safe for use in concrete.

- It is recommended to test more aggregates using the proposed method to identify if the test is not applicable to certain types of aggregates.

\section{Acknowledgments}

The funding for this research was provided by a grant from the Ministry of Transportation, Ontario (MTO) Highway Infrastructure Innovation Fund. The opinions expressed in this paper are those of the authors and may not necessarily reflect the views and policies of MTO. The authors would like to acknowledge the support of Ms. Carole Anne McDonald of MTO for her help in describing the aggregate samples. This research was also supported by the Ryerson University Faculty of Engineering and Architectural Science Dean's Research Fund. The authors acknowledge the support of both organizations.

\section{References}

[1] A. Lugg and D. Probert, "Mundic-type problems: a building material catastrophe," Construction and Building Materials, vol. 10, no. 6, pp. 467-474, 1996.

[2] J. S. Chinchon, A. Lopez-Soler, X. Querol and R. Vaquer, "Determination of pyrrhotite (Fe1-xS) occurring in aggregates by $\mathrm{X}$ ray fluorescence," Cement and Concrete Research, vol. 20, no. 3, p. 394-397, 1990.

[3] J. Berard, R. Roux and M. Durand, "Performance of concrete containing a variety of black shale," Canadian Journal of Civil Engineering, no. 2, pp. 58-65, 1974. 
[4] R. E. Oberholster and J. E. Kruger, "Investigation of alkali-reactive, sulphide-bearing and by-product aggregates," Bulletin of Engineering Geology and the Environment, vol. 30, pp. 273-277, 1984.

[5] A. Rodrigues, J. Duchesne and B. Fournier, "A new accelerated mortar bar test to assess the potential deletarious effect of sulfide-bearing aggregate in concrete," Cement and Concrete Research, vol. 73, pp. 96-110, 2015.

[6] A. Rodrigues, J. Duchesne, B. Fournier, B. Durand, M. Shehata and P. Rivard, "Evaluation Protocol for Concrete Aggregates Containing Iron Sulfide Minerals," ACI Materials Journal, vol. 113, no. 3, pp. 349-359, 2016.

[7] A. Rodrigues, J. Duchesne and B. Fournier, "Damage evaluation of two different concrete mix designs containing sulfide-bearing aggregates," in 36th International Conference on Cement Microscopy, Milan, Italy, 2014.

[8] A. Rodrigues, J. Duchesne and B. Fournier, "Petrographic characterization of the deterioration products of a concrete containing sulfide bearing aggregates; a particular case of internal sulphate attack," in 35th International Conference on Cement Microscopy, Chicago, USA, 2013.

[9] A. Rodrigues, J. Duchesne, B. Fournier, B. Durand, P. Rivard and M. Shehata, "Mineralogical and chemical assessment of concrete damaged by the oxidation of sulfidebearing aggregates: Importance of thaumasite formation on reaction mechanisms," Cement and Concrete Research, vol. 42, no. 10, p. 1336-1347, 2012.

[10] A. Rodrigues, J. Duchesne and B. Fournier, "Microscopic analysis of the iron sulfide oxidation products used in concrete aggregates," in 34th International Conference on Cement Microscopy, Halle-Saale, Germany, 2012.

[11] V. Ramos, A. Rodrigues, B. Fournier and J. Duchesne, "Development of a quick screening staining test for detecting the oxidation potential of iron sulfide-bearing aggregates for use in concrete," Cement and Concrete Research, vol. 81, p. 49-58, 2016. 
[12] K. Wille and R. Zhong, "Investigating the deterioration of basement walls made of concrete in ct," 2016.

[13] H. F. Steger, "Oxidation of sulphide minerals VII. Effect, of temperature and relative humidity on the oxidation of pyrrhotite," Chemical Geology, vol. 35, pp. 281-295, 1982.

[14] C. Ayora, S. Chinchon and A. Aguada, "Weathering of iron sulfides and concrete alteration: thermodynamic model and observation in dams from central Pyrenees, Spain," Cement and Concrete Research, vol. 28, no. 9, p. 1223-1235, 1998.

[15] A. Shayan, "Deterioration of a concrete surface due to the oxidation of pyrite contained in pyritic aggregates," Cement and Concrete Research, vol. 18, pp. 723-730, 1988.

[16] P. Hagelia, R. Sibbick, N. Crammond and C. Larsen, "Thaumasite and secondary calcite in some Norwegian concretes," Cement and Concrete Composition, vol. 25, pp. 1131-1140, 2013.

[17] A. Tagnit-Hamou, M. Saric-Coric and P. Rivard, "Internal deterioration of concrete by the oxidation of pyrrhotitic aggregates," Cement and Concrete Research, vol. 35, no. 1, pp. 99107, 2005.

[18] R. E. Oberholster, P. Dutoit and J. L. Pretorius, "Deterioration of Concrete Containing a Carbonaceous Sulphide-Bearing Aggregate," in Proceedings of the Sixth Annual International Conference, Albuquerque, New Mexico USA, 1984.

[19] N. Belzile, Y. W. Chen, M. F. Cai and Y. Li, “A review on pyrrhotite oxidation,” Journal of Geochemical Exploration, vol. 84, pp. 65-76, 2004.

[20] M. P. Janzen, R. V. Nicholson and J. M. Scharer, "Pyrrhotite reaction kinetics: Reaction rates for oxidation by oxygen, ferric iron, and for nonoxidative dissolution," Geochemica et Cosmochimica Acta, vol. 64, no. 9, pp. 1511-1522, 2000.

[21] S. Chinchon-Paya, A. Aguado and S. Chinchon, "A comparative investigation of the degradation of pyrite and pyrrhotite under simulated laboratory conditions," Engineering Geology, vol. 127, pp. 75-80, 2012. 
[22] P. E. Grattan-Bellew and W. J. Eden, "Concrete deterioration and floor heave due to biogeochemical weathering of underlying shale," Canadian Geotechnical Journal, vol. 12, pp. 372-378, 1975.

[23] S. Shnorhokian, "Development of a Quantative Accelerated Sulphate Attack Test for Mine Backfill,” McGill University, 2009.

[24] P. Chirita, M. Descostes and M. L. Schlegel, "Oxidation of FeS by oxygen-bearing acidic solutions," Journal of Colloid and Interface Science, vol. 321, no. 1, pp. 84-95, 2008.

[25] T. Schmidt, A. Leemann, E. Gallucci and K. Scrivener, "Physical and microstructural aspects of iron sulfide degradation in concrete," Cement and Construction Research, vol. 41, no. 3, pp. 263-269, 2011.

[26] J. R. Craig, “The metamorphism of pyrite and pyritic ores: an overview," Mineralogical Magazine, vol. 57, pp. 3-18, 1993.

[27] A. Rodrigues, J. Duchesne and B. Fournier, "Quantitative assessment of the oxidation potential of sulfide-bearing aggregates in concrete using an oxygen consumption test," Cement and Concrete Composition, vol. 67, no. 15, pp. 93-100, 2016.

[28] H. G. Midgley, “The staining of concrete by pyrite," Magazine of Concrete Research, vol. 10, pp. 75-78, 1958.

[29] ASTM C641, Standard Test Method for Iron Staining Materials in Lightweight Concrete Aggregates, West Conshohocken, PA: ASTM International, 2009.

[30] S. Seaton., "Study of causes and prevention of staining and pop-outs in cinder concrete," Am. Concr. Inst., vol. 44, pp. 361-380, 1948.

[31] D. Whitney and B. W. Evans, "Abbreviations for names of rock-forming minerals," American mineralogist, vol. 95, pp. 185-187, 2010.

[32] ASTM D75 / D75M-14, Standard Practice for Sampling Aggregates, West Conshohocken, PA: ASTM International, 2014. 
[33] ASTM C702-98, Standard Practice for Reducing Samples of Aggregate to Testing Size, Conshohozken, PA: ASTM International, 1998.

[34] ASTM C1260-14, Standard Test Method for Potential Alkali Reactivity of Aggregates (Mortar-Bar Method), West Conshohocken, PA: ASTM International, 2014.

[35] S. Frais, Y.-L. Ng and K. Gulabivala, "Some factors affecting the concentration of available chlorine in commercial sources of sodium hypochlorite," International Endodontic Journal, vol. 34, pp. 206-215, 2001.

[36] Canadian Standards Association (CSA), A23.1-14/A23.2-14 - Concrete materials and methods of concrete construction / Test methods and standard practices for concrete, CSA, 2014. 